\title{
ATTENUATION OF GENETIC PROGRESS UNDER CONTINUED SELECTION IN POULTRY
}

\author{
I. MICHAEL LERNER and EVERETT R. DEMPSTER \\ University of California, Berkeley
}

Received 20.x.50

In the absence of disturbing factors, a phenotypic trait whose genetic variance is determined by alleles at a single locus will respond to selection pressure until fixation of the most desirable allele is attained. Presumably similar exhaustion of genetic variation may account for deceleration and eventual cessation of gains from selection of a character under polygenic control. It is, however, also possible that other factors may interfere with the realisation of genetic gains long before the limitations imposed by the decrease in genetic variability enter the picture to a significant degree. Attention to a number of factors possibly responsible for this phenomenon has been drawn by Lush (I945), Dempster and Lerner (1949), Lerner (1950) and others. In general these factors represent mechanisms falling into one of two categories :-

(a) Negative correlation of the selected trait with fitness, and

(b) non-additive gene action (and possibly genotype-environment interaction).

The first of these may take the form of a negative correlation in individuals chosen as parents between genotypes for the selected trait and the numbers of surviving offspring, or of a negative correlation in their offspring between genotypes for the selected trait and the probabilities of survival to maturity.

Both $(a)$ and $(b)$ are basically varieties of what Lerner (I950) has called genetic homeostasis, or the property of a population at an adaptive peak to resist changes in its genetic composition. The more common and evolutionarily effective form of genetic homeostasis is, of course, selection for fitness which tends to maintain the population at an adaptive peak. Under artificial selection, however, differences in what may be called natural fitness are not necessarily any longer the sole determinants of selective advantage. Thus if artificial selection for a character not intrinsically connected with viability, rate of maturation, and fecundity is practiced, the individuals excelling in the desired trait and thus selected to be the parents of the next generation are not always those possessing the greatest fitness under natural selection. If they are actually less fit in the latter sense than individuals nearer the mean of the population with respect to the trait under artificial selection, it is clear that some of the artificial 
selection pressure applied will be dissipated in overcoming the pull of natural selection in the opposite direction from that of artificial selection. Under such circumstances, relaxation of artificial selection would result in the complete or partial return of the population to its original level with respect to the trait under selection.

Examples of this situation are provided in the long-range Drosophila selection experiments of Mather and Harrison (1949), of which only one needs to be cited here. From an $F_{2}$ cross between two strains of Drosophila melanogaster previously not subjected to artificial selection, a line selected for a high number of abdominal chæta was established. Reasonably regular gains were obtained for 20 generations, but concurrently there occurred a reduction in fertility of such severity as to threaten the extinction of the line. Selection was suspended at this point and the line reproduced en masse, with the result that chrta number reverted in the course of 5 generations to approximately the original level. With minor fluctuations this level was henceforth maintained for over 100 further generations.

At the 24th generation a selected line was again started from the mass culture. This line responded to selection without a loss in fertility and when selection was once more suspended ro generations later no drop in chæta number was observed.

Mather and Harrison interpreted these results in terms of Mather's (194I, 1942, 1943) theory of polygenic balance. Briefly speaking, the gist of it as applied to this particular instance lies in the existence of linked combinations of genes some of which affect chæta number and others fitness. Under a high selection pressure for chæta number alleles with adverse effects on fitness were carried to high frequencies, being, so to speak, locked into blocks with desirable gross effects on chæta number. With suspension of the pressure for the latter trait, natural selection for fitness could once more operate to its full extent. In the meantime between the $24^{\text {th }}$ and the $34^{\text {th }}$ generation, blocks of different genic content arose as a result of crossing-over, so that a new adaptive peak at a higher level of chæta number came into existence.

Whether Mather's particular theory of polygenic balance or a broader basis such as suggested by Hazel (see p. 239 in Lerner, 1950) for the induction of negative genetic correlations between two traits under selection (chæta number and fitness in the Drosophila example described) be accepted, it seems that should mechanisms of this type be in operation in any given selection experiment, they might be detected by investigating rates of reproduction of individuals. Data for such an investigation are available from two experiments conducted with poultry. The purpose of the present communication is to examine them in the light of our previous remarks in order to determine, if possible, which of the three general factors * (exhaustion of variability,

* A fourth factor may be noted in the reduction of selection pressure. However, unless selection for other traits is introduced this factor must be in turn produced by one or more of the three listed ones. 
balance between fitness and a trait under artificial selection, and non-additive variability) are of greatest significance in decreasing the efficiency of genetic gains under selection. In the first of these experiments, that on shank length, an actual plateau has been reached, although it is possible that the plateau is only a temporary one, such as obtained by Mather and Harrison in some of their selected lines. In the second experiment, on egg production, it is impossible to say at the present time whether progress has stopped. Nevertheless, the attrition of the artificial selection pressure by natural selection in the opposite direction is still subject to investigation even if only a reduction of the rate of gain per unit of pressure applied is obtained.

\section{SELECTION FOR SHANK LENGTH}

Lerner (1943) has previously reported on the earlier phases of this experiment. It consisted of the establishment of a line of Single Comb White Leghorns selected for long shanks at maturity from the University of California production-bred flock which later served as an unselected control. Table I shows the progress attained from

TABLE I

Results of selection for increased shank length

\begin{tabular}{|c|c|c|c|c|c|}
\hline \multirow{2}{*}{ Year } & \multicolumn{2}{|c|}{ Production line } & \multicolumn{2}{|c|}{ Size line } & \multirow{2}{*}{$\begin{array}{c}\text { Difference } \\
\text { in shank } \\
\text { length, } \mathrm{cm}\end{array}$} \\
\hline & $\begin{array}{c}\text { Number of } \\
\text { birds }\end{array}$ & $\begin{array}{l}\text { Mean shank } \\
\text { length, } \mathrm{cm} .\end{array}$ & $\begin{array}{c}\text { Number of } \\
\text { birds }\end{array}$ & $\begin{array}{l}\text { Mean shank } \\
\text { length, } \mathrm{cm} .\end{array}$ & \\
\hline 1938 & 368 & $9 \cdot 69$ & & $\ldots$ & $\ldots$ \\
\hline I 939 & 274 & 9.62 & 84 & $9 \cdot 9^{2}$ & 0.30 \\
\hline 1940 & 137 & 9.55 & $89 *$ & $9 \cdot 92$ & 0.37 \\
\hline 1941 & 346 & $9 \cdot 37$ & гоб & $10 \cdot 20$ & 0.83 \\
\hline 1942 & 260 & $9 \cdot 46$ & 119 & 10.29 & 0.83 \\
\hline 1943 & 543 & $9 \cdot 42$ & $19^{1}$ & 10.46 & $I \cdot 04$ \\
\hline I 944 & 184 & $9 \cdot 4 \mathrm{I}$ & 75 & $10 \cdot 73$ & $\mathrm{I} \cdot 32$ \\
\hline 1945 & $3^{82}$ & $9 \cdot 4^{8}$ & $6 \mathrm{r}$ & 10.84 & $1 \cdot 3^{6}$ \\
\hline 1946 & 309 & $9 \cdot 44$ & 88 & $10 \cdot 7 \mathrm{I}$ & $1 \cdot 27$ \\
\hline 1947 & 377 & $9.77 \dagger$ & 59 & $10 \cdot 73 \dagger$ & 0.96 \\
\hline $194^{8}$ & 471 & $9 \cdot 89 \dagger$ & 53 & $10 \cdot 96 \dagger$ & $1 \cdot 07$ \\
\hline 1949 & 473 & 9.53 & $9^{2}$ & $10 \cdot 78$ & $1 \cdot 25$ \\
\hline $1939^{-1} 944$ & \multirow{2}{*}{\multicolumn{3}{|c|}{$\begin{array}{l}\text { Change per year (least squares regression) } \\
\text { Change per year (least squares regression) }\end{array}$}} & . & $0 \cdot{ }_{1} 88$ \\
\hline I $943-1949$ & & & & . & -0.007 \\
\hline
\end{tabular}

* Six birds inadvertently omitted in Lerner's (1943) report.

$\dagger$ Measured by different observer.

selection from 1938 to 1949 . Only females were measured in this experiment, the selection of males being based on sister and progeny averages. All of the measurements of the birds up to 1946 were made by one of us (I. M. L.). In 1947 and 1948 a research assistant 
undertook this task. In r949 the measurements were carried out jointly by the original observer and another research assistant. There is considerable reason to believe that the technique of measurement used in $1947-4^{8}$ led to overestimates of $0 \cdot 1-0 \cdot 2 \mathrm{~cm}$. Since this discrepancy was undoubtedly a constant one for all birds measured, the last column of table $\mathrm{I}$ is probably a more accurate indication of the gains attained than the column giving the mean shank lengths for the selected line. In any case it may be clearly seen that selection was effective for the first seven generations, after which little if any further gains were obtained. This is clearly demonstrated by the average gains per year obtained in the first seven years as compared with that in the second (based on the regression of shank length on year, and allowing a one-year overlap in the two periods), which appear at the bottom of the last column in the table.

Table 2 presents an analysis of variability of the successive generations of the selected line. The heritability figures given are estimates from intra-class half and full sister correlations. They represent a

TABLE

Genetic parameters of size line

(omitting families with only one offspring)

\begin{tabular}{|c|c|c|c|c|c|c|}
\hline \multirow{2}{*}{ Year } & \multirow{2}{*}{$\begin{array}{l}\text { Number } \\
\text { of birds }\end{array}$} & \multirow{2}{*}{$\begin{array}{l}\text { Coefficient } \\
\text { of } \\
\text { inbreeding } \\
(F)\end{array}$} & \multicolumn{2}{|c|}{ Heritability } & \multirow{2}{*}{$\begin{array}{c}\text { Phenotypic } \\
\text { variance }\end{array}$} & \multirow{2}{*}{$\begin{array}{c}\text { Genetic } \\
\text { variance } \\
\text { (raw) }\end{array}$} \\
\hline & & & raw & $\begin{array}{l}\text { corrected } \\
\quad \text { for } F\end{array}$ & & \\
\hline I 939 & 84 & 0 & 0.887 & 0.887 & 0.244 & 0.216 \\
\hline I $94^{\circ}$ & 87 & 0.029 & $(-0.049)$ & $(-0.050)$ & 0.168 & $(-0.008)$ \\
\hline 194 I & 99 & 0.072 & 0.262 & 0.288 & 0.174 & 0.046 \\
\hline I 942 & II 2 & 0. I I 2 & 0.374 & 0.442 & $0.24 \mathrm{I}$ & 0.090 \\
\hline I 943 & 182 & 0.145 & 0.053 & 0.063 & $0 \cdot 186$ & 0.010 \\
\hline I 944 & 69 & 0.189 & 0.243 & 0.318 & 0.465 & 0.113 \\
\hline 1945 & 52 & 0.222 & $0 \cdot 649$ & $(1 \cdot 023)$ & 0.280 & 0.182 \\
\hline $\begin{array}{l}945 \\
1946\end{array}$ & 78 & 0.273 & 0.564 & 0.983 & 0.152 & 0.086 \\
\hline 1947 & 45 & 0.299 & 0.105 & O.I 57 & 0.187 & 0.020 \\
\hline I 948 & 34 & 0.3 I I & $0.15^{8}$ & 0.247 & $0.23^{8}$ & 0.038 \\
\hline I 949 & 90 & $0 \cdot 344$ & $0 \cdot 289$ & 0.519 & $0.23^{2}$ & 0.067 \\
\hline I $939^{-1} 944$ & Average & 0.097 & 0.260 & 0.287 & 0.229 & 0.059 \\
\hline I $943-1949$ & Average & 0.231 & 0.269 & 0.410 & 0.236 & 0.062 \\
\hline
\end{tabular}

considerable amount of variation from year to year, but the comparison between the average variability in the first and second halves of the period of selection indicates that the amount of genetic variance and the degree of heritability have not materially changed in the course of selection. This is substantiated by intra-sire daughter-dam regressions which lead to heritability estimates of $0.332 \pm 0.16$ for the first and $0.542 \pm 0 \cdot 20$ for the second half of the selection period. It may be parenthetically noted that the heritability of shank length 
in the parent flock (the production line) was found to be $0 \cdot 38$, a figure comparable to the averages corrected for inbreeding in table 2.*

It seems that consanguineous mating practiced in the selection line has not reduced the genetic variance to the extent which might be indicated by the magnitude of the coefficient of inbreeding, paralleling the previous findings of Shoffner (1948). The significance of this observation cannot, however, be adequately assessed at this time.

We may thus see that in this experiment response to selection has ceased, although the genetic variability available for selection to operate on has not been exhausted. The question then arises as to which of the mechanisms noted as the possible explanations of such situations can be held responsible for the phenomenon observed.

To simplify the computations bearing on this question, we may confine our analysis to the offspring of dams used as parents for the first time, since the inclusion of re-mated dams would introduce selection criteria (in particular their reproductive performance and progeny tests) which would complicate the situation. In the material at hand, 82.5 per cent. (770 out of 933 birds) of the offspring in the years

TABLE 3

Analysis of offspring from pullet dams

\begin{tabular}{|c|c|c|c|c|c|c|c|}
\hline \multirow{2}{*}{ Year } & \multirow{2}{*}{$\begin{array}{l}\text { Number } \\
\text { of } \\
\text { selected } \\
\text { dams }\end{array}$} & \multirow{2}{*}{$\begin{array}{c}\text { Number } \\
\text { of } \\
\text { offspring }\end{array}$} & \multirow{2}{*}{$\begin{array}{c}\text { Index } \\
\text { of } \\
\text { fitness * }\end{array}$} & \multirow{2}{*}{$\begin{array}{c}\text { Average } \\
\text { shank } \\
\text { length of } \\
\text { offspring, } \\
\mathrm{cm} \text {. }\end{array}$} & \multicolumn{2}{|c|}{$\begin{array}{c}\text { Selection } \\
\text { differential }\end{array}$} & \multirow{2}{*}{$\begin{array}{r}\text { Ratio } \\
\text { realised } \\
\text { expected }\end{array}$} \\
\hline & & & & & $\begin{array}{l}\text { Expected } \\
\text { cm. }\end{array}$ & $\begin{array}{l}\text { Realised } \\
\mathrm{cm} .\end{array}$ & \\
\hline I 940 & I 5 & 70 & $4 \cdot 67$ & $9 \cdot 9$ I & 0.480 & 0.476 & 0.99 \\
\hline I 94 I & I 9 & $8_{5}$ & 4.47 & I 0.18 & 0.349 & 0.335 & 0.96 \\
\hline I 942 & I 8 & 64 & 3.56 & $10 \cdot 22$ & $0 \cdot 194$ & O. IOO & 0.56 \\
\hline 1943 & 33 & $19 \mathrm{I}$ & $4 \cdot 63$ & 10.46 & 0.425 & 0.417 & 0.98 \\
\hline I 944 & 23 & 57 & $2 \cdot 48$ & 10.73 & 0.558 & 0.505 & 0.91 \\
\hline I 945 & $2 \mathrm{I}$ & 55 & $2 \cdot 62$ & $10.8 \mathrm{I}$ & $0 \cdot 378$ & 0.385 & $\mathrm{I} \cdot \mathrm{O} 2$ \\
\hline $194^{6}$ & 23 & 71 & 3.09 & 10.66 & 0.273 & $0.13^{2}$ & $0.4^{8}$ \\
\hline 1947 & 28 & 44 & 1.57 & $\mathrm{I} 0.8 \mathrm{I}$ & 0.455 & 0.422 & 0.93 \\
\hline 1948 & 23 & $5 \mathrm{I}$ & $2 \cdot 22$ & 10.94 & 0.339 & $0 \cdot 190$ & 0.56 \\
\hline I 949 & $2 \mathrm{I}$ & 82 & $3 \cdot 12$ & 10.79 & 0.429 & 0.309 & 0.72 \\
\hline I $940-$ I 945 & $\ldots$ & Average & 3.75 & $\ldots$ & 0.404 & $0 \cdot 3^{80}$ & $0 \cdot 94$ \\
\hline I $944-$ I 949 & $\ldots$ & Average & 2.47 & $\ldots$ & 0.407 & $0 \cdot 314$ & 0.77 \\
\hline
\end{tabular}

* Number of offspring measured per dam, based on a standard 4-week hatching period.

I 940-49 were from dams mated in their first year of life. As it may be seen from table 3 omission of the remaining 163 measured birds does not materially affect the trend of selection progress. Accordingly all of the computations referred to in table 3 were confined to 770 bird:

* This value was computed for us by Mr Fred T. Schultz by pooling data from halfsister correlations for the years I $942-1949$, involving measurements on 2983 birds. Mr Schultz also found that maternal effects account for 6-7 per cent. of the total variation, confirming the conclusions formulated by Hazel and Lamoreux (I 947) and Lerner and Cruden (I95I). 
The first mechanism suggested lies in the lowered reproductive rate (as measured by the number of offspring reaching maturity) of parents with genotypes for longer shanks. It is quite apparent from the index of fitness in table 3 that this possibility exists, since the average number of offspring per dam has dropped from 3.75 in the period of gains to 2.47 in the period of the plateau. The question, however, is whether the elimination of offspring was differential or independent of the genotypes of the selected parents. We can attack this problem first on the phenotypic level, since the answer for the female parents at least does not present a difficult problem. If we consider the birds selected as parents of the next generation in any year we can readily compute the expected selection differential by subtracting from their average shank length the average of their own generation. If we weight the shank lengths of these females by the number of their offspring which survived until the time of measurement, the weighted average obtained would represent the realised selection differential. The ratio of the realised to the expected selection differential provides a measure of association between fitness and shank length. If it is less than unity, it means that among the selected birds those with longer shanks produce, on the average, less offspring than those with shorter shanks. This would provide a strong indication that natural selection for fitness does indeed operate in the opposite direction from artificial selection for longer shanks.

It may be seen that the selection pressure attempted, although variable from year to year, did not change much, if at all, between the period in which gains were realised and the one in which no further progress was obtained. On the other hand, the realised selection differential showed a considerable drop. The ratio between the two was 0.94 for the period ending 1945 , and only 0.77 for the last six years. Although the gain realised in any year does not always reflect the variation in this ratio, it seems quite clear that by and large selection for fitness of dams has been in the opposite direction to selection for shank length, only mildly opposing it at first and fairly severely later.

It may be of interest to determine at what stage of the reproductive cycle the differential elimination of the offspring of the relatively longer shanked dams occurs. This can be readily done by computing the selection differentials realised at each of the successive stages. Thus the identical procedure used for computing the selection differential realised at the time of measurement can be applied to selection differentials at the time of incubation (based on the number of eggs laid by the dams), at the time of determination of fertility (based on the number of fertile eggs), and at hatching time (based on the number of chicks obtained). The results are summarised in the following table.

It may thus be seen, that differences in hatching power are the ones primarily responsible for the variation in the reproductive rate 
of dams having different shank length. Variation in egg production, fertility of eggs, and post-hatching mortality is not involved in the first period, although both egg production and chick survival differences contribute to the drop in the realised selection differential in the second.

Selection differentials

\begin{tabular}{|c|c|c|c|c|c|}
\hline Period & Expected & $\begin{array}{c}\text { Based on } \\
\text { eggs set }\end{array}$ & $\begin{array}{c}\text { Based on } \\
\text { fertile eggs }\end{array}$ & $\begin{array}{c}\text { Based on } \\
\text { chicks } \\
\text { hatched }\end{array}$ & Realised \\
\hline $1940-45$ & 0.404 & 0.408 & 0.410 & 0.385 & 0.380 \\
$1944-49$ & 0.407 & 0.382 & 0.382 & 0.337 & 0.314 \\
\hline
\end{tabular}

The computations made so far strongly suggest that a polygenic balance of some sort may be in operation. It must, however, be realised that the negative correlation between shank length and reproductive fitness deduced to exist is on a phenotypic level. The attrition in the genotypic selection differential may be even greater than the ratio of 0.77 in table 2 indicates. To check this possibility computations were carried out for the expected and the realised selection differentials of family averages (including the dams) in a manner exactly similar to that described above for individual measurements. Family averages should provide somewhat better estimates of the genotypes of the dams than do their phenotypes. Indeed, the realised selection differential in the second period computed on this basis is an even smaller fraction of the expected selection differential. This is shown in the following table and suggests that the negative correlation between number of offspring and shank length may be greater along the genotypic than along the environmental pathway.

\begin{tabular}{|c|c|c|c|}
\hline Period & $\begin{array}{c}\text { Expected selection } \\
\text { differential, cm. }\end{array}$ & $\begin{array}{c}\text { Realised selection } \\
\text { differential, cm. }\end{array}$ & Ratio \\
\hline $194 \mathrm{I}-45$ & $0 \cdot 137$ & $0 \cdot 134$ & 0.98 \\
$1944-49$ & $0 \cdot I_{55}$ & $0 \cdot 105$ & 0.68 \\
\hline
\end{tabular}

\section{THE ATTRITION OF SELECTION PRESSURE}

The observed decrease in the phenotypic selection differential should lead to a greater reduction in gain if the correlation is entirely genetic than if it is due in part to an environmental component of like sign. It is possible to demonstrate, as shown in the appendix, that, on the extreme assumption of an entirely genetic correlation and on the basis of certain simplifying postulates (such as that all genetic variance is additive), the form of adverse natural selection being discussed would reduce the genotypes of offspring from their 
expected values by $0.03 \mathrm{~cm}$. per generation in the early and by $0.1 \mathrm{r} \mathrm{cm}$. in the late periods of selection. Thus the additional loss in the second period as compared to the first would be about $0.11-0.03$, or $0.08 \mathrm{~cm}$. The assumptions underlying this estimate, which is nearly half of the gain per generation $(0 \cdot 188 \mathrm{~cm}$.) attained in the early period, are likely to err in a direction leading to the attribution of too great an influence to differential fecundity, but bias in the reverse direction is not precluded. It may perhaps be agreed that the lower fecundity of dams with genotypes for higher shank length definitely results in some reduction in gains, that not improbably the reduction due to this cause may be nearly half the rate of gain achieved in the early period of selection, and that a still greater effect; though rather unlikely, is not disproved by the data.

In addition to the adverse natural selection between families due to larger dams having fewer offspring, there would also be some selection within families if the decrease in number of measured offspring per dam in the plateau period of selection, as compared to the early period, is due in part to the elimination within each family of genotypes for longer shank length. The intensity of this selection depends on unknown factors, such as the degree of possible negative correlation between genotype for hatchability and genotype for shank length. The following calculations based on postulates, very unfavourable for attaining gains, show that the within-families natural selection probably accounts for only a small portion of the decrease in rate of gain under artificial selection. The number of pullets per roo fertile eggs set has been found to be 18.8 in the plateau period as compared to 24.3 in the early period, a drop of 22.6 per cent. Elimination of the 22.6 per cent. of the highest individuals in a normal distribution lowers the mean by 0.3885 standard deviations. However, it is extremely unlikely that the elimination is confined to the highest genotypes only, because the heritability of hatchability must be considerably lower than unity, as must also be the genetic correlation between hatchability and shank length. The value 0.5 is an overestimate of the product of the square root of the heritability and genetic correlation so that the decrease in genotype for shank length is almost certainly less than $0.5 \times 0.3885$ or 0.1943 standard deviations. This figure does not take into account the finite size of the families, which further decreases the shift in mean due to elimination of better genotypes. The genetic variance within families may be taken as approximately equal to one half the total genetic variance or (from table 2) as $0.062 / 2=0.031$; the genetic standard deviation is the square root of this or 0.176 . Multiplying the latter figure by $0 \cdot 1943$ yields 0.034 , which is less than a fifth of the gain per year achieved during the early years of selection. This component of natural selection for short shanks might then account for as much as, although probably less than, a fifth of the observed decrease in rate of gain.

It may be next argued that differential fertility of the males (on 
which measurements were not made largely because only a small percentage are normally raised to maturity) is responsible for a further reduction in the expected selection differential. This possibility can be disposed of by computations analogous to those made for the females, except for the fact that only family selection differentials can be utilised (the males selected as first-time sires being chosen on the basis of the average phenotypes of their sisters). The expected and realised selection differentials and their ratios for the periods I 94 I -44 and I 943-49 (there being only one male in I940 not previously mated) are as follows :--

\begin{tabular}{|c|c|c|c|c|}
\hline Period & $\begin{array}{c}\text { Per cent. of all } \\
\text { offspring in } \\
\text { period }\end{array}$ & $\begin{array}{c}\text { Fxpected, } \\
\mathrm{cm} .\end{array}$ & $\begin{array}{c}\text { Realised, } \\
\mathrm{cm} .\end{array}$ & $\begin{array}{c}\text { Realised : } \\
\text { expected }\end{array}$ \\
\hline $\mathrm{I} 94 \mathrm{I}-45$ & 0.82 & 0.242 & 0.246 & $\mathrm{I} \cdot 02$ \\
$\mathrm{I} 944-49$ & 0.77 & 0.197 & 0.217 & $\mathrm{I} \cdot \mathrm{I} 0$ \\
\hline
\end{tabular}

The situation differs from that of the female parents in that the ratio of the realised to the expected selection differential in both periods exceeded unity, and in that the ratio shows a slight increase in the later period. In other words, while attrition of selection pressure applied on the maternal side can be demonstrated to have occurred, the paternal side seems to be free from this effect. This is also borne out indirectly by analyses of variance of the number of offspring (relative to the average in any given year) measured per dam. It may be seen from the following table that it is the dam rather than the sire that is mainly responsible for the negative correlation between genotype for shank length and the number of offspring, since the variance component due to differences between sires is in each of the periods analysed less than a twentieth of that due to the differences between dams, and not significant in terms of the latter.

\begin{tabular}{|c|c|c|c|c|c|c|}
\hline Period & $\begin{array}{l}\text { Sour } \\
\text { variz }\end{array}$ & $\begin{array}{l}\text { e of } \\
\text { nce }\end{array}$ & & $\begin{array}{l}\text { Degrees of } \\
\text { freedom }\end{array}$ & $\begin{array}{c}\text { Mean } \\
\text { square }\end{array}$ & $\begin{array}{l}\text { Variance } \\
\text { component }\end{array}$ \\
\hline \multirow[t]{2}{*}{$194^{\circ}-45$} & $\begin{array}{l}\text { Dams } \\
\text { Sires }\end{array}$ & . & . & $\begin{array}{r}\text { I I I } \\
\text { I } 2\end{array}$ & $\begin{array}{l}0.850 \\
1 \cdot 147\end{array}$ & $\begin{array}{l}0.85^{0} \\
0.04^{1}\end{array}$ \\
\hline & Total & . & . & I 23 & 0.879 & $0.89 \mathrm{I}$ \\
\hline \multirow[t]{2}{*}{ I $944-49$} & $\begin{array}{l}\text { Dams } \\
\text { Sires }\end{array}$ & . & . & $\begin{array}{r}\text { I } 19 \\
\text { I } 4\end{array}$ & $\begin{array}{l}\mathrm{I} \cdot 2 \mathrm{I} 2 \\
\mathrm{I} \cdot 083\end{array}$ & $\begin{array}{r}\mathrm{I} \cdot 2 \mathrm{I} 2 \\
-0 \cdot 019\end{array}$ \\
\hline & Total & . & . & I 33 & $I \cdot I 98$ & $I \cdot I 93$ \\
\hline
\end{tabular}

It may thus be seen that with respect to shank length, where a plateau has been reached before genetic variability was exhausted, 
we have evidence that genetic homeostasis is mediated at least in part by natural selection operating on the reproductive fitness (hatchability and to some extent egg production and chick viability) of the dams chosen. Should this process and the possible intra-family offspring elimination be insufficient to account for cessation of progress-and their estimated magnitudes suggest that they are not likely to account for much more than half of the reduction in the rate of gain-non-additive gene action must be postulated.

This can take a number of different forms. For instance, if dominance of genes for long shanks is involved, it is possible that the frequency of the recessives has been reduced to such an extent that dominance deviations began to contribute significantly to nonadditive genetic variance (in relative if not in absolute terms of magnitude). While there is no evidence for dominance in the crosses between the selected and the control lines reported by Lerner (1943), this possibility cannot be entirely dismissed.

Another type of non-additiveness may be found if overdominance exists, or, in other words, if selection has been directed towards heterozygotes. When sufficient data are available, this possibility can be checked by the technique suggested by Lerner (1950) of comparing the phenotypic variation of daughters of long and shortshanked dams mated to the same sire.

Finally, some form of epistasis may be present. The data at hand are inadequate to answer the question of non-additive gene action, but experiments involving relaxation of selection, further crosses between lines, and diallel matings are being initiated for this purpose.

\section{SELECTION FOR EGG PRODUCTION}

We may next turn to the second of the experiments available for this study, that on the selection for a high hen-housed average egg production (production index). The details of this project have been elaborated in several previous publications, all of the pertinent details having been summarised by Lerner (1950). Table 4 gives the size of the population and the production index for each year. The latter is an average measure of egg production based on the total performance of an unculled group of pullets from the beginning of lay through 3oth September of their second year of life. For reasons discussed in the section of this paper dealing with the shanklength selection experiment, the present study of selection differentials is confined to dams mated for the first time. Since within the period reported upon here, these in an overwhelming majority were two years old, the population studied has been restricted to dams of this age. Thus the performance of offspring reported in table 4 refers to birds hatched two years later than their dams.

Some of the columns in table 4 may require further comment. The production index of the selected dams (column 5) is, of course, 


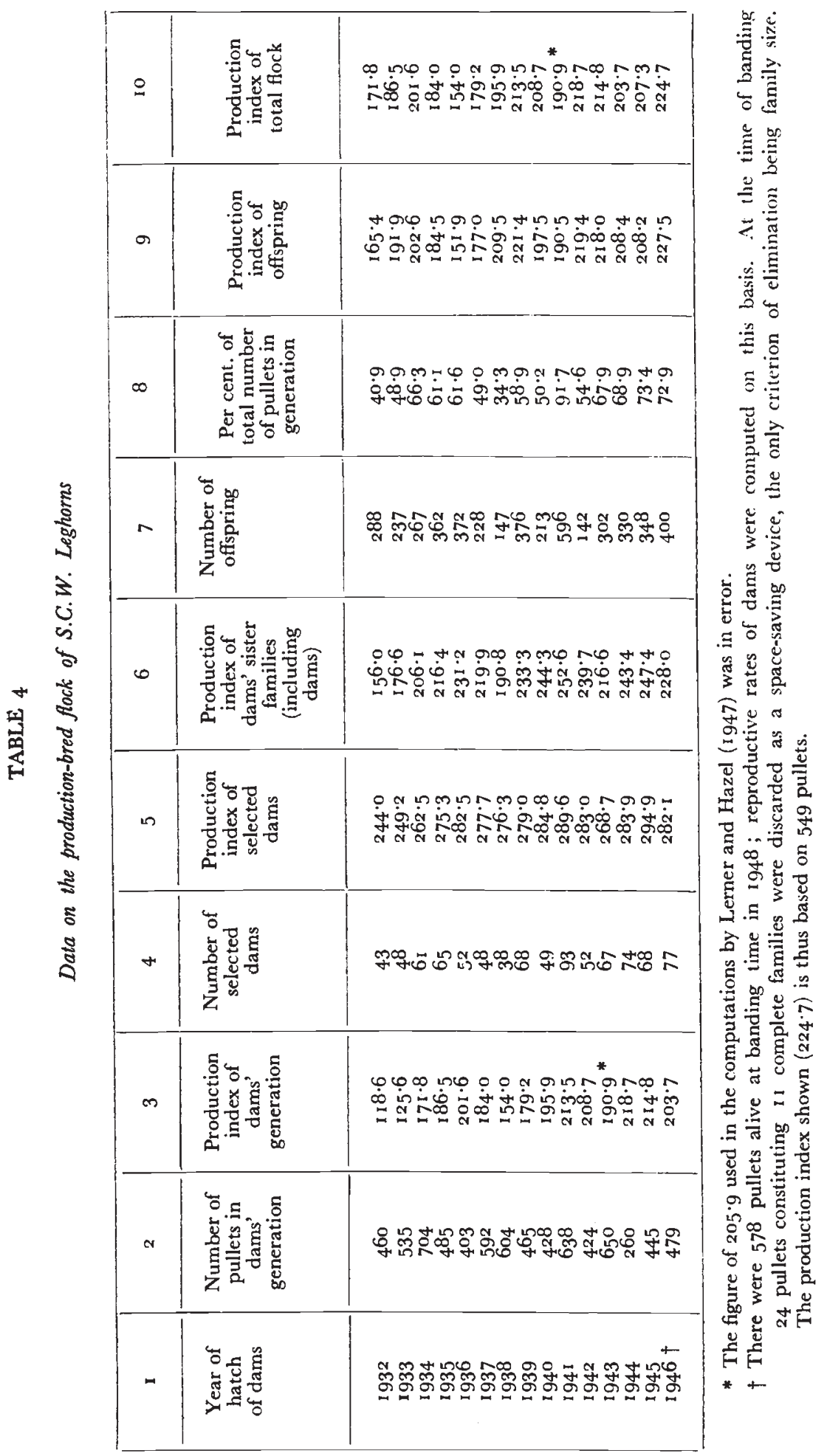


equivalent to the "survivors' production", since only birds living through the first laying year were available for selection in the second laying year. Since the primary criterion of selection was the family average, the production indexes of families selected are given in column 6 . The number of female offspring in the next generation. from the number of dams specified in column 4 is given in column 7 , and the percentage that they form of the total nimber in the flock of their particular generation is shown in column 8. Finally columns 9 and Io show the comparison between the production indexes of the group of offspring from 2-year-old dams and of the total population. It may be noted here in passing that the weighted average production index of the offspring of dams mated for the first time exceeds that of all other dams by approximately 4 eggs. The direction of this difference runs counter to the indications previously obtained from a restricted sample by Lerner and Hazel (1947), but tends to support the ideas advanced by Dempster and Lerner (1947) regarding the limited contribution progeny testing has made to the advances in egg production obtained in this flock.

It is impossible to say with certainty whether the flock has reached a plateau with respect to the production index. The inter-year variation appears to be so great as to preclude the possibility of establishing this point. It seems reasonably clear, however, that the rate of advance has tended to decline. Thus, the regression of gain on year in the period $1933-42$ has been found to be 6.00 eggs, while that for the period 1939-48, only $2 \cdot 95$ eggs.* The question then still may be brought up whether the balance between artificial selection in one direction and natural selection in the other has played any role in the attenuation of the rate of gain.

It may first be noted without entering any details that unpublished data of Lerner and Cruden indicate no exhaustion of genetic variability in the production index (as judged from intra-year heritability estimates). The situation thus parallels that found in the shanklength selection experiment.

The reduction in selection pressure has similarly been found to be moderately small in extent. The figures appearing at the bottom of table 5 indicate that the average selection differential from $1934-42$ (or 1932-40 if indicated by the year of hatch of the dams rather than of the offspring) was 99.7 eggs on the individual, and $39^{\circ} 0$ on the family basis. For the later period (1940-48), the comparable figures were 82.9 and 35.6 eggs respectively. This reduction obviously cannot account for a 50 per cent. drop in the annual rate of gain on any hypothesis of exclusively additive gene action.

The computations leading to the answer to the question posed

* Lerner and Hazel (1 947) gave the regression for the period of 1933-44 as 5.37 eggs. The error for 1943 noted in the footnote to table 4 calls for a revision of their figure to 5 . 5 eggs, which, of course, in no way affects either their or subsequent conclusions by Dempster and Lerner (1947) and Lerner (1950). 
regarding the possible role of polygenic or other form of balance for egg production are analogous to those carried out for shank length. However, instead of the ratio between the realised and the expected selection differentials, it is more illuminating to compute the difference between them. As shown in table 5 the birds with higher egg

TABLE 5

Selection differentials for egg production

\begin{tabular}{|c|c|c|c|c|c|}
\hline \multirow{2}{*}{$\begin{array}{l}\text { Year of } \\
\text { hatch } \\
\text { of dams }\end{array}$} & \multirow{2}{*}{$\begin{array}{l}\text { Realised } \\
\text { individual } \\
\text { selection } \\
\text { differential }\end{array}$} & \multicolumn{2}{|c|}{$\begin{array}{c}\text { Realised minus expected } \\
\text { individual selection } \\
\text { differential }\end{array}$} & \multirow{2}{*}{$\begin{array}{l}\text { Realised } \\
\text { family } \\
\text { selection } \\
\text { differential }\end{array}$} & \multirow{2}{*}{$\begin{array}{c}\text { Realised } \\
\text { minus } \\
\text { expected } \\
\text { family } \\
\text { selection } \\
\text { differential }\end{array}$} \\
\hline & & Total & Within sires & & \\
\hline $193^{2}$ & $126 \cdot 9$ & $1 \cdot 5$ & -0.2 & $33 \cdot I$ & $-4 \cdot 3$ \\
\hline 1933 & $126 \cdot 1$ & 2.5 & $4 \cdot 5$ & 49.5 & $-1 \cdot j$ \\
\hline 1934 & $9^{1 \cdot 2}$ & 0.5 & $0 \cdot 9$ & $36 \cdot 3$ & $2 \cdot 0$ \\
\hline 1935 & $89 \cdot 4$ & 0.6 & 0.8 & $29 \cdot 6$ & -0.3 \\
\hline 1936 & $78 \cdot 5$ & $-2 \cdot 4$ & $-2 \cdot 6$ & $28 \cdot 4$ & $-1 \cdot 2$ \\
\hline 1937 & $93 \cdot 5$ & $-0 \cdot 2$ & $-1 \cdot 1$ & 39.4 & $3 \cdot 5$ \\
\hline $193^{8}$ & 119.0 & $-3 \cdot 3$ & $-2 \cdot 9$ & $36 \cdot 2$ & -0.6 \\
\hline 1939 & $99 \cdot 4$ & -0.4 & 0.9 & $52 \cdot 4$ & $-1 \cdot 7$ \\
\hline I 940 & $92 \cdot 4$ & 3.5 & 0.4 & $5^{1} \cdot 3$ & $2 \cdot 9$ \\
\hline 1941 & $77^{\circ} 0$ & 0.9 & $2 \cdot 1$ & $39 \cdot 9$ & 0.8 \\
\hline I 942 & 73.5 & -0.8 & $-2 \cdot 0$ & $28 \cdot 5$ & $-1 \cdot 5$ \\
\hline 1943 & $79 \cdot 2$ & $1 \cdot 4$ & 0.6 & $28 \cdot 4$ & $2 \cdot 7$ \\
\hline I 944 & $66 \cdot 5$ & $1 \cdot 3$ & $2 \cdot 3$ & $23 \cdot 3$ & $-1 \cdot 4$ \\
\hline 1945 & $80 \cdot 4$ & 0.3 & $3 \cdot 1$ & $33 \cdot 9$ & $1 \cdot 3$ \\
\hline 1946 & $79 \cdot 4$ & $\mathrm{I} \cdot \mathrm{O}$ & I. 6 & $24 \cdot 1$ & $-0 \cdot 2$ \\
\hline $1932-1940^{*}$ & $99 \cdot 7$ & 0.22 & $0 \cdot 13$ & $39^{\circ} \mathrm{o}$ & -0.37 \\
\hline $193^{8-1} 94^{6} *$ & $82 \cdot 9$ & $0 \cdot 66$ & $1 \cdot 27$ & $35 \cdot 6$ & $0 \cdot 31$ \\
\hline
\end{tabular}

* Weighted according to number of offspring.

production actually produced somewhat more female offspring entering laying pens, since the realised selection differential exceeded the expected one by 0.22 eggs in the first, and by 0.66 eggs in the second period considered. Elimination of the possible effects of the sires on these figures, by computing the selection differentials within sires, leaves this conclusion unchanged, the excess of the realised over the expected selection differential being 0.13 and 1.27 eggs for the two respective periods.

Similar considerations of the family selection differentials confirms the lack of any balance mechanism. Undoubtedly, neither the figure of -0.37 eggs for the first period nor that of 0.31 eggs for the second for the differences between the realised and the expected differentials deviate significantly from zero. Furthermore, the change in the direction of the difference is opposite to the one expected should the balance mechanism have been involved in the reduction of obtained gains.

There seems to be but little doubt then that, in the case of selection 
for egg production, attrition of artificial selection pressure by natural selection for fitness has not played any significant role in this flock up to this time. It seems premature at this stage to enter speculations regarding the possible role of non-additive gene action in limiting the rate of genetic progress in the production index.

Before proceeding with a general discussion, comparable figures for two other economically important characters may be given. The traits considered are egg weight and sexual maturity, and from the data given in table 6 it should be apparent that once more there is

TABLE 6

Selection differentials for egg weight and sexual maturity

\begin{tabular}{|c|c|c|c|c|c|c|}
\hline \multirow{3}{*}{$\begin{array}{l}\text { Year of } \\
\text { hatch } \\
\text { of dams }\end{array}$} & \multicolumn{3}{|c|}{ March egg weight } & \multicolumn{3}{|c|}{ Days to sexual maturity } \\
\hline & \multirow{2}{*}{$\begin{array}{l}\text { Mean of } \\
\text { selected } \\
\text { dams, gms. }\end{array}$} & \multicolumn{2}{|c|}{$\begin{array}{l}\text { Realised minus } \\
\text { expected selection } \\
\text { differential }\end{array}$} & \multirow{2}{*}{$\begin{array}{l}\text { Mean of } \\
\text { selected } \\
\text { dams days }\end{array}$} & \multicolumn{2}{|c|}{$\begin{array}{l}\text { Realised minus } \\
\text { expected selection } \\
\text { differential }\end{array}$} \\
\hline & & Total & $\begin{array}{l}\text { Within } \\
\text { sires }\end{array}$ & & Total & $\begin{array}{c}\text { Within } \\
\text { sires }\end{array}$ \\
\hline I 932 & $5^{6 \cdot 3}$ & -0.6 & -0.6 & $188 \cdot 7$ & $\mathrm{I} \cdot \mathrm{O}$ & $\mathrm{I} \cdot 3$ \\
\hline 1933 & $57 \cdot 5$ & $-0 \cdot 1$ & -0.4 & $184 \cdot 2$ & 0.9 & $-0 \cdot I$ \\
\hline 1934 & $57 \cdot 6$ & $-0 \cdot I$ & $-0 \cdot 3$ & $\mathrm{I} 8 \mathrm{I} \cdot 8$ & $-2 \cdot 5$ & $-2 \cdot 7$ \\
\hline 1935 & $56 \cdot 9$ & $-0 \cdot 1$ & $0 \cdot 0$ & $175 \cdot 3$ & $0 \cdot 1$ & $-0 \cdot 2$ \\
\hline I 936 & $56 \cdot 1$ & 0.1 & $0 \cdot 0$ & $170 \cdot 4$ & $3 \cdot 6$ & $2 \cdot 7$ \\
\hline I 937 & $57 \cdot 6$ & 0.3 & $0 \cdot 4$ & $167 \cdot 6$ & 0.3 & 0.9 \\
\hline I $93^{8}$ & $57 \cdot 5$ & $0 \cdot 2$ & -0.2 & I $66 \cdot 9$ & $-3 \cdot 3$ & $-3 \cdot 2$ \\
\hline I 939 & $57 \cdot 7$ & $0 \cdot 0$ & $-0 \cdot 8$ & I $70 \cdot 4$ & 0.9 & 0.4 \\
\hline 1940 & $58 \cdot 2$ & -0.5 & -0.6 & $168 \cdot 4$ & I. 3 & $2 \cdot I$ \\
\hline I 941 & $5^{6 \cdot 3}$ & -0.6 & $-0 \cdot 3$ & $169 \cdot 9$ & $-I \cdot I$ & $-I \cdot I$ \\
\hline 1942 & $55^{\cdot 7}$ & -0.3 & $-0 \cdot 2$ & $162 \cdot 2$ & I $\cdot O$ & $I \cdot I$ \\
\hline I 943 & $57 \cdot 9$ & 0.0 & -0.1 & I $77 \cdot 9$ & $-0 . I$ & -0.6 \\
\hline I 944 & $55^{\cdot} 6$ & -0.2 & $0 \cdot 2$ & 173.2 & 0.7 & 0.2 \\
\hline 1945 & $5^{6 \cdot 5}$ & $0 \cdot I$ & 0.3 & I $57 \cdot 8$ & $I \cdot I$ & 0.8 \\
\hline 1946 & $55 \cdot 3$ & -0.3 & 0.4 & $168 \cdot 2$ & -0.8 & -0.2 \\
\hline 1 $932-1946 *$ & $\cdots$ & -0.17 & -0.21 & $\cdots$ & 0.26 & $0 \cdot 1 \mathrm{I}$ \\
\hline
\end{tabular}

* Weighted according to number of offspring.

no evidence that the balance between each of the traits and fitness plays a major role. It is, however, possible that here the balance may exist between these traits and egg production. Thus the selection pressure applied to the flock was primarily based on the number of eggs and viability. If birds laying too small or too large eggs do not lay or live as well as those with an intermediate size, the artificial selection pressure for egg weight may not have been unidirectionally applied and on the average was close to zero. The case of sexual maturity may fall in the same category, especially in view of the non-linear correlation between it and egg number observed by Knox (1930). 


\section{GENERAL CONSIDERATIONS AND SUMMARY}

It is an attractive hypothesis, and one that has met with a degree of success, that the construction of efficient selection indexes and the rough estimation of the rates of improvement to be achieved by selection of measurable characters of economic importance in domestic animals can be based on the postulates that the genetic variance is in large part additive in nature, and that such non-additive genetic variance as may exist has the same significance with respect to gains from selection as environmental variations from individual to individual. Although this simple model may be adequate in the early stages of a selection programme, it is certainly conceivable that the genetic and environmental relationships could become more complicated after sufficiently prolonged selection. Some theoretical possibilities are that the additive variance will approach exhaustion, that non-additive variation may increase to some extent, that it may no longer be neutral in its effects but may necessitate a positive selection intensity to prevent retrogression, and that negative correlations may appear between genotypes for the selected characters including components of fitness which, by definition, are subject to natural selection. All these possible hindrances may be studied on the genetic level in terms of variation and correlation; in some cases no doubt they may be effectively approached in terms of physiological limits and incompatibilities. Certainly, many attacks from many different standpoints will be required for a general understanding of the problems raised. The present paper attempts an analysis of some of the factors that may lead to a lowered response to selection in two poultry experiments of many years' duration.

It is shown above that selection for long shanks in a small population of White Leghorns over a span of eleven years (equivalent to eleven generations as far as the pullet and cockerel selections are concerned) led to a considerable increase in shank length during the first half and apparent cessation of gains during the latter half of the period. During this time there was no net decrease of phenotypic variability of shank length, nor are the estimates of heritability and of genetic variance, based on half and full sib correlations, any lower during the last half of the experiment than during the early period. Two possible reasons for the cessation of gains suggest themselves, namely, a change in the nature of the genetic variance and a counteracting tendency of natural selection. It is planned to test the first of these possibilities, which cannot be adequately evaluated from present data, in future experiments. The second possibility has been shown to exist to some degree. The data and the computations indicate that nearly one-half of the rate of gain achieved in the first period of selection may be counteracted in the second period by a negative correlation between genotypes of the dams for shank length and hatchability of their eggs, and that selective elimination among the 
offspring of individual dams might lead to some further reduction which, however, is probably considerably less than one-fifth of the early rate of gain. Some of the postulates on which the calculations are based may correspond only in a rough way with the actual situation. For example, it is unlikely that the regression of genotype for shank length on number of offspring of dams is strictly linear; it is entirely possible that the highest genotypes for shank length produce very few offspring and that the average and lower genotypes found among the dams produce approximately equal numbers. A non-linearity of this general type could result in greater attrition of gains than is indicated on the basis of the postulates adopted for computation. Due to uncertainties of this type, as well as to sampling errors, it cannot be positively affirmed that natural selection for shorter shanks does not account in toto for the cessation of gains; on the other hand, the data show with a high degree of probability that adverse natural selection is at least in part responsible. It is reasonable to suppose that the negative correlation between genotypes for fitness and for shank length has been caused by the prolonged selection for both, a possibility that has been predicted from theoretical considerations by a number of authors (see, for example, Lerner, 1950), and shown to occur to a high degree in the long-term selection experiments with Drosophila by Mather and Harrison (1949).

The selection for production index has continued for a longer period of time, although the number of generations involved is not necessarily different from that of the shank length experiment, largely because pullet selection was not used in the former. The size of the production flock is much greater and the inbreeding has been less as has also been the intensity of genetic selection due to the much lower heritability of production index as compared to shank length. In some ways, therefore, the production index experiment, may be considered to be in a somewhat earlier stage than the shank length experiment, although the possible physiological limit of an egg a day is approached by some birds, whereas no obvious physiological limit to shank length is as yet apparent. Although there are some indications that the rate of increase in production index in the later years was less than in the early years (or possibly gain has ceased entirely), the magnitude of the inter-seasonal variation precludes a definite judgment on this point. On the other hand, the dams with a high production index have as many offspring as (in fact, slightly more than) dams with a lower production index; such change in this respect as the data indicate, although probably statistically insignificant, is in the direction of an increased positive correlation between genotypes for production index and fitness. The notable difference between the two experiments in correlation between fitness and the character selected for may be due, in part at least, to the fact that production index includes one aspect of fitness, so that the component that these two characters have in common would favour a positive correlation 
between them. In addition, there has been some direct selection for number of offspring produced by a dam. However, neither the common component of fitness and production index, nor the direct selection for number of offspring, could preclude a decrease in correlation on continued selection. A priori it would be expected that some negative correlation should have been induced between production index and some aspect of fitness that does not directly enter into the production index, as, for example, the proportion of fertile eggs that hatch. It is planned to present an analysis of this relationship elsewhere.

\section{APPENDIX}

\section{Calculated reduction in gain due to differential fecundity of dams}

As indicated in the text, the computations are based on the postulate that the correlation between shank length and number of offspring of dams is entirely along the genotypic pathway; i.e. that the environmental variation, with genotype fixed, would not cause either a positive or negative correlation between these two variables. If such an environmentally caused correlation does in fact exist, our estimate of reduction in rate of gain will tend to be too high, except that if the environmental component were positive in sign and the genetic component negative, the bias would be reversed.

In fig. I, the ordinates represent phenotypes and the abscissæ represent genotypes. Heritability is taken as 0.269 , the estimate given in table 2 for the plateau period, and the environmental standard deviation is used as a convenient unit of measurement for both the phenotypic and genotypic scales. The straight line at $45^{\circ}$ is the regression of phenotype for shank length on genotype for shank length, the mean phenotype being equal to the genotype by definition. The two ellipses are contours of equal density at one and two standard deviations, normality being assumed.

Although some family selection has been utilised, the calculations are based on the postulate that the selection of pullets for parentage is based solely on individual shank length and that a certain proportion of the pullets of each generation is required for use as dams. This neglect of family selection leads to some overestimation of the inhibiting effects of the differential reproduction, but whatever error may be due to this necessary simplification is considerably reduced (although not completely eliminated) by taking, for purposes of calculation, not the actual proportion of pullets utilised as parents but the somewhat larger proportion that would just account (on the assumption of normality) for the observed phenotypic differential in mass selection. Thus, for the plateau period of selection, the average unweighted phenotypic selection differential is $0.407 \mathrm{~cm}$. or 0.8378 standard deviations. The tail of a unit normal distribution whose mean is equal to this value has an area of 0.4753 . This proportion of the population (consisting of birds having the longest shanks) is indicated 
in the figure by the area above the horizontal dashed line. This area therefore represents pullets used as dams, and the area below the dashed line, pullets not so used. The regression of phenotype on genotype of this selected population is not quite linear and is shown by the curved line drawn through the circled points. The values of these points were computed to a close approximation by the following method. The normal distribution of genotypes was divided by ordinates

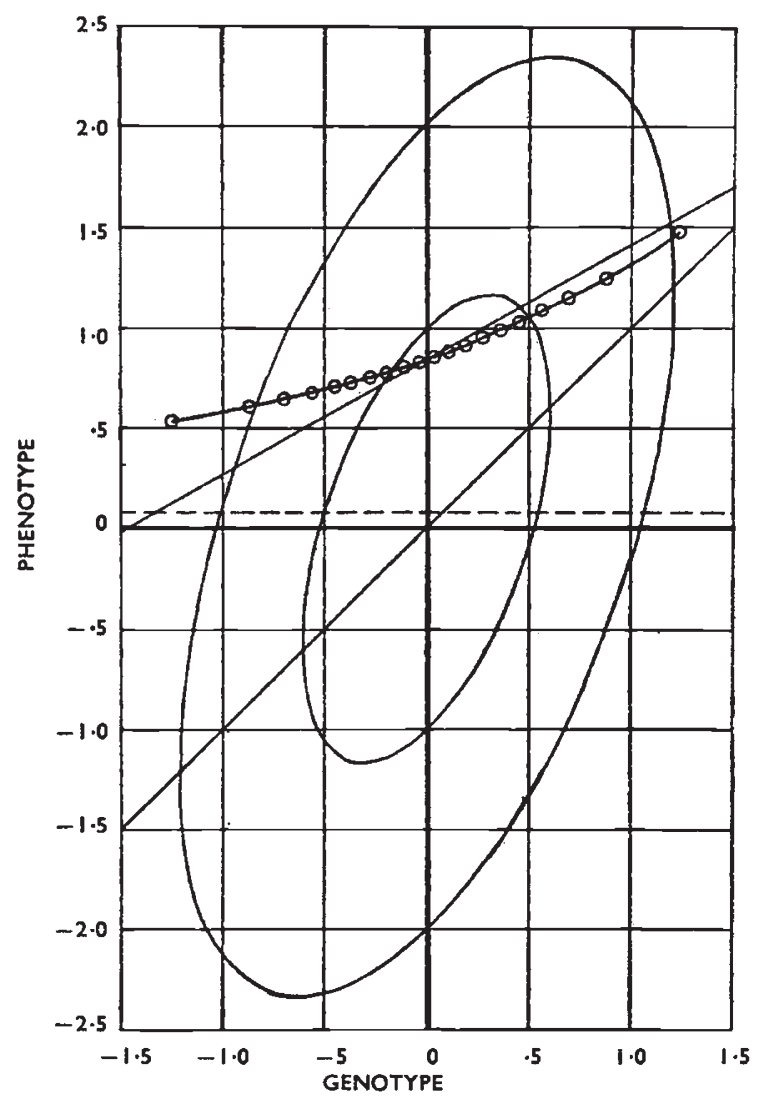

Fic. I.-Regressions of phenotype on genotype for shank length. The regression for the whole population is the straight line at $45^{\circ}$. The regression for the group of pullets selected as dams (represented by the area above the dashed line) is the curved line through the small circles. For further details see text.

into 20 equal areas, and the individuals in each area treated as though concentrated at the mean. These mean values were marked off on the horizontal genotype scale in the figure. Within each segment there is a normal distribution of phenotypes (indicated by the vertical scale) whose mean is the same as the genotypic mean of the segment, and whose standard deviation is the environmental standard deviation. Each of these distributions is truncated by the selection, the point of truncation being indicated by the dashed horizontal line mentioned before. It is a simple matter to compute 
the mean phenotypes of the truncated distributions above the dashed line, and these means have been indicated on the diagram by the circles. The area of each distribution above the dashed line is also computed for weighting purposes in subsequent calculations. The weighted means of the phenotypes and genotypes of these points are 0.9794 and 0.2628 as compared to 0.9799 and 0.2636 computed directly, indicating that the division into twenty segments will give an approximation of ample precision for purposes of rough estimation.

The Symbol $G i$ is defined as the genotype and $P i$ as the phenotype for shank length characteristic of dams in segment $i$ of the normal distribution, the genotypes and phenotypes being expressed as deviations from the unweighted means for all dams; $n_{G i}$ represents the relative number of offspring (i.e. the actual number of offspring divided by the mean number for all dams) characteristic of genotype $G i$; and the regression, which we postulate to be linear, of $n_{G i}$ on genotype for shank length is represented by the symbol $b$. Then $n_{G i}=\mathrm{I}-b G i$, and the mean weighted phenotype (i.e. the difference between the expected and realised phenotypic selection differentials) is given by the following expressions, where $\mathrm{M}$ indicates mean value of:

$$
M\left[n_{G i} P_{i}\right]=M\left[\left(1-b G_{i}\right) P_{i}\right]=-M\left[b G_{i} P_{i}\right]
$$

The computation of values of $P_{i}$, indicated by the circles in the figure, has already been described. It is found that a regression of $b=\mathbf{I} \cdot 8 \mathrm{I}$ (in environmental standard deviation units) is required to account for the observed difference between expected and realised phenotypic selection differentials of 0.2239 in environmental standard deviation units (corresponding to $0.093 \mathrm{~cm}$. as shown in table 3 ). This regression in turn yields a drop in weighted, as compared with unweighted, genotypes of dams of 0.5383 in environmental standard deviations, or 0.224 in $\mathrm{cm}$.

Since, on the basis of the postulates given above, the regression of phenotype on genotype among the selected dams evidently does not deviate very greatly from linearity, the estimate just obtained may be compared with one easily computed on the assumption of linearity. The variance of the phenotypes of selected dams, considered as represented by the toe of a normal distribution having 47.53 per cent. of the total area, is $35^{\circ} \mathrm{OI}$ per cent. of the variance of the whole population, a reduction of 64.99 per cent. The corresponding reduction in genotypic variance is the product of 64.99 per cent. and the heritability $(0.269)$ or 17.48 per cent., leaving a variance of 82.52 per cent. of that in the whole population. Since the regression of genotype on phenotype is not altered by direct selection of the latter (and since a correlation may be expressed in terms of regression as $\left.r_{y x}=b_{y x}\left(\sigma_{x} / \sigma_{y}\right)\right)$ the correlation in the selected population is reduced, as compared to that in the whole population, by the factor $\sqrt{0 \cdot 350 \mathrm{I}} / \sqrt{\mathrm{0} \cdot 825^{2}}$ and becomes this factor multiplied by the square root of the heritability $(\sqrt{0 \cdot 269})$. The regression of phenotype on 
genotype in the selected group may now be computed as the product of the correlation and the ratio of the standard deviations of the phenotype and genotype, which reduces to (o.350 I)/(o.8252) or 0.4243 . If therefore, the regression of number of offspring on genotype for shank length reduces the weighted mean phenotype of dams by $0.93 \mathrm{~cm}$., it must have reduced the weighted mean genotype by $0.093 / 0.4243$ or $0.219 \mathrm{~cm}$. This is sufficiently close to the figure of 0.224 obtained by the more laborious process of dividing a normal distribution into segments of equal area. Applying the simpler procedure to the data of the early period during which gains were achieved, a figure of 0.059 is obtained.

Since about half the gains may be expected to be achieved by selection of dams, and since, as shown in the main text, there is no evidence for differential reproduction of sires of different genotypic shank length, the reduction in the genotypes of offspring should be about half those computed for the genotypes of the dams. Thus the loss in gain due solely to the fact that the better dams have fewer offspring is $0.224 / 2$ or $0 . \mathrm{II} \mathrm{cm}$. in the period of the plateau, and $0 \cdot 059 / 2$ or $0.03 \mathrm{~cm}$. in the period of gains. The difference between these two figures, $0.08 \mathrm{~cm}$. then represents the amount of reduction in gain per generation attributable to the adverse effect of natural selection under the postulated conditions.

\section{REFERENCES}

DEMPSTER, E. R., AND I. M. LERNER. 1947. The optimum structure of breeding flocks. Genetics, 32, 555-579.

DEMPSTER, E. R., AND 1. M. LERNER. 1949. Selection problems in animal breeding. Proc. Berkeley Symp. Math. Stat. Prob., pp. 481-483.

HAZEL, L. N., AND W. F. LAMOREUX. 1947. Heritability, maternal effects and nicking in relation to sexual maturity and body weight in White Leghorns. Poultry Sci., 26, 508-514.

KNox, c. w. 1930. Factors influencing egg production. Iowa Agr. Exp. Sta. Res. Bull., 119, 3 I I-332.

LERNER, I. M. I943. Inheritance of size in Single-Comb White Leghorns. 7 . Agr. Res., 67, 447-457.

LERner, i. M. 1950. Population Genetics and Animal Improvement. xviii $+34^{2}$ pp. Cambridge.

LERNER, I. M., AND CRUDEN, D. I $95 \mathrm{I}$. The heritability of egg weight : the advantages of mass selection and of early measurements. Poultry Sci., 3o, (34-4 r).

LERNER, I. M., AND HAZEL, L. N. 1947. Population genetics of a poultry flock under artificial selection. Genetics, 32, 325-339.

LUSH, J. L. 1945. Animal Breeding Plans. viii +443 pp. Ames, Iowa: Collegiate Press.

MATHER, K. I941. Variation and selection of polygenic characters. F. Genet., 4I, 159-I 93 .

MATHER, K. 1942. The balance of polygenic combinations. 7. Genet., 43, 309-335.

MATHER, K. 1943. Polygenic inheritance and natural selection. Biol. Rev., 18, 32-64. MATHER, K., AND HARRISON, B. J. I 949 . The manifold effect of selection. Heredity, $3,1-52,131-162$.

SHOFFNER, R. N. I 948 . The variation within an inbred line of S.C.W. Leghorns. Poultry Sci., 27, 235-236. 